\title{
Avaliação das habilidades técnicas da equipe de enfermagem no atendimento da parada cardiorrespiratória
}

\author{
Evaluation of the technical skills of the nursing staff in attending cardiopulmonary arrest \\ Evaluación de las habilidades técnicas del personal de enfermería en la atención de la parada
} cardiopulmonar

Recebido: 25/02/2021 | Revisado: 05/03/2021 | Aceito: 09/03/2021 | Publicado: 17/03/2021

Bianca Nunes Bueno da Silva

ORCID: https://orcid.org/0000-0002-8284-4391 Fundação Educacional do Município de Assis, Brasil E-mail: biabueno16@outlook.com

Caroline Lourenço de Almeida

ORCID: https://orcid.org/0000-0002-6043-9301 Fundação Educacional do Município de Assis, Brasil E-mail: caroline_lat@hotmail.com

Eleine Aparecida Penha Martins

ORCID: https://orcid.org/0000-0001-6649-9340 Universidade Estadual de Londrina, Brasil E-mail: eleinemartins@gmail.com

Daniel Augusto da Silva

ORCID: https://orcid.org/0000-0002-2716-6700 Fundação Educacional do Município de Assis, Brasil

E-mail: daniel.augusto@unifesp.br

Maria Gorete Nicolette Pereira

ORCID: https://orcid.org/0000-0001-9862-6279

Universidade Estadual de Londrina, Brasil

E-mail: goreteepaixao@hotmail.com

Gisele Andrade Menolli

ORCID: https://orcid.org/0000-0002-8413-2857

Universidade Estadual de Londrina, Brasil

E-mail: gimenolli@gmail.com

Ana Cândida Martins Grossi Moreira

ORCID: https://orcid.org/0000-0003-1487-6903

Universidade Estadual do Norte do Paraná, Brasil

E-mail: anacandidagrossi@uenp.edu.br

\begin{abstract}
Resumo
A parada cardiorrespiratória é um dos fatores responsáveis pela elevação da morbimortalidade, mesmo em situações ou locais que possam garantir um atendimento ideal. O objetivo deste estudo é avaliar o conhecimento e as habilidades técnicas da equipe de enfermagem quanto a reanimação cardiopulmonar. Trata-se de um estudo quantitativo, descritivo, transversal. Desenvolvida em uma Unidade de Pronto Atendimento em uma cidade do interior paulista. No período de julho a agosto de 2020. A amostra foi de 32 participantes. Foram elaborados instrumentos para coleta de dados sociodemográficos, e que avaliaram o desempenho; como habilidades e atitudes do profissional, quanto o conhecimento teórico-prático sobre o assunto abordado, sendo construído conforme a literatura e protocolos de atendimento da American Heart Association. Os dados foram analisados por meio de análise estatística descritiva. A maioria dos participantes são do sexo feminino (27; 84,4\%), na faixa etária entre 20 e 30 anos $(14 ; 43,8 \%)$, Técnicos em Enfermagem $(15 ; 46,9 \%)$. Sobre o resultado do Teste de Conhecimento sobre Ressuscitação Cardiopulmonar, composto por 15 afirmações verdadeiras ou falsas, observou-se uma questão com 100\% de acerto pelos participantes. Há déficit e lacunas de conhecimento da equipe de enfermagem no atendimento a ressuscitação cardiopulmonar.
\end{abstract}

Palavras-chave: Parada cardíaca; Enfermagem; Conhecimento.

\begin{abstract}
Cardiorespiratory arrest is one of the factors responsible for the increase in morbidity and mortality, even in situations or places that can guarantee an ideal care. The aim of this study is to assess the knowledge and technical skills of the nursing team regarding cardiopulmonary resuscitation. This is a quantitative, descriptive, cross-sectional study. Developed in an Emergency Care Unit in a city in the interior of São Paulo. From July to August 2020. The sample was 32 participants. Instruments were developed to collect sociodemographic data, and which evaluated performance; as skills and attitudes of the professional, as well as theoretical and practical knowledge on the subject addressed, being
\end{abstract}


built according to the literature and protocols of care of the American Heart Association. The data were analyzed using descriptive statistical analysis. Most participants are female $(27 ; 84.4 \%)$, aged between 20 and 30 years $(14 ; 43.8 \%)$, Nursing Technicians $(15 ; 46.9 \%)$. Regarding the result of the Knowledge Test on Cardiopulmonary Resuscitation, composed of 15 true or false statements, an issue with $100 \%$ correct answers was observed by the participants. There is a deficit and gaps in the knowledge of the nursing staff in the care of cardiopulmonary resuscitation.

Keywords: Heart arrest; Nursing; Knowledge.

\section{Resumen}

La parada cardiorrespiratoria es uno de los factores responsables del aumento de la morbilidad y la mortalidad, incluso en situaciones o lugar que pueden garantizar una atención ideal. El objetivo de este estudio es evaluar los conocimientos y habilidades técnicas del equipo de enfermería en relación con la reanimación cardiopulmonar. Se trata de un estudio cuantitativo, descriptivo y transversal. Desarrollado en una Unidad de Atención de Emergencias en una ciudad del interior de São Paulo. De julio a agosto de 2020. La muestra fue de 32 participantes. Se desarrollaron instrumentos para recolectar datos sociodemográficos, y que evaluaban el desempeño; como habilidades y actitudes del profesional, así como conocimientos teóricos y prácticos sobre el tema abordado, siendo construidos de acuerdo a la literatura y protocolos de atención de la American Heart Association. Los datos se analizaron mediante análisis estadístico descriptivo. La mayoría de los participantes son mujeres (27; 84,4\%), con edades comprendidas entre los 20 y 30 años $(14 ; 43,8 \%)$, técnicos de enfermería $(15 ; 46,9 \%)$. En cuanto al resultado del Test de Conocimientos en Reanimación Cardiopulmonar, compuesto por 15 afirmaciones verdaderas o falsas, los participantes observaron un problema con $100 \%$ de aciertos. Existe un déficit y lagunas en el conocimiento del personal de enfermería en el cuidado de la reanimación cardiopulmonar.

Palabras clave: Paro cardíaco; Enfermería; Conocimiento.

\section{Introdução}

A parada cardiorrespiratória (PCR) é um dos fatores responsáveis pela elevação da morbimortalidade, mesmo em situações ou locais que possam garantir um atendimento ideal ao indivíduo vítima de PCR. A assistência de emergência, nos ambientes pré e intra hospitalar, exige dos profissionais de saúde uma ação imediata e eficaz para a obtenção de sucesso nesse atendimento (Nacer \& Barbieri, 2015; Rocha, Oliveira, Cavalcante, Silva, \& Hates, 2012).

Durante a PCR existe o risco de ocorrer lesões cerebrais irreversíveis e a cada segundo eleva-se a probabilidade de morte; e cessação da circulação para os órgãos vitais. O diagnóstico de PCR deve ser dado o quanto antes, e iniciado as medidas necessárias para retorno imediato da circulação sanguínea para diminuir os riscos de lesões e melhorar a sobrevida destes pacientes (Silva, Araújo, Almeida, Pereira, Carvalho, \& Abreu, 2017), neste sentido, a PCR é considerada um problema de saúde pública mundial, sendo que no Brasil existe estimativas de 200.000 casos de PCR por ano, nestes metade ocorre em ambientes hospitalares (Nacer \& Barbieri, 2015).

A assistência de enfermagem ao paciente em PCR quando não ocorre com qualidade e precisão, pode levar a complicações que são entendidas como eventos que geram algum tipo de prejuízo à saúde do paciente, podendo ser motivada ou não por falhas humanas. Portanto, o papel da equipe de enfermagem torna-se de suma importância, podendo afetar diretamente o resultado final quanto ao estado do paciente, sendo certo afirmar que a atuação deste profissional é determinante para o sucesso do atendimento ao paciente (Lucena \& Silva, 2017).

No caso da enfermagem ou área da saúde, onde o cuidado precisa ser realizado de forma holística e individualizado, considerando particularidades de cada ser humano, a necessidade do conhecimento obtido pela desconstrução do corpo humano fica mais evidente, justificado pela necessidade do estudo mais complexo de todas as suas partes formadoras, cujas partes se integram e se inter-relacionam (Carabetta Junior, 2016).

Neste sentido, cria-se a necessidade de entendermos como está o conhecimento dos profissionais da enfermagem quanto ao atendimento a vítima em parada cardiorrespiratória, e se existem lacunas deste conhecimento que devam ser melhoradas, para que possa ocorrer um atendimento de qualidade e sem sequelas à essas vítimas.

Assim, o objetivo deste estudo é avaliar o conhecimento e as habilidades técnicas da equipe de enfermagem quanto a reanimação cardiopulmonar. 


\section{Metodologia}

Trata-se de um estudo quantitativo, descritivo, transversal. Desenvolvida em uma Unidade de Pronto Atendimento em uma cidade do interior paulista. No período de julho a agosto de 2020.

A população da pesquisa foi composta por 50\% dos funcionários, que aceitaram participar, sendo que atuam na unidade 72 funcionários da enfermagem, nas 24 horas de atendimento da instituição, destes 15 são enfermeiros, 25 técnicos de enfermagem e 32 auxiliares de enfermagem. Porém, 8 funcionários foram excluídos da pesquisa, por estarem de atestado; afastamento ou férias, conforme os critérios de exclusão da pesquisa. Dos 64 funcionários aptos em participar da pesquisa, apenas 32 (50\%) aceitaram participar. Adotaram-se como critérios de inclusão todos os profissionais da enfermagem que tivesse vínculo empregatício na unidade, e como exclusão os profissionais que se encontra-se em férias, atestado ou licença.

Foram elaborados instrumentos para coleta de dados sociodemográficos, e que avaliaram o desempenho; como habilidades e atitudes do profissional, quanto o conhecimento teórico-prático sobre o assunto abordado, sendo construído conforme a literatura e protocolos de atendimento da American Heart Association (American Heart Association, 2020; 2015).

Devido todo o cenário enfrentado pela pandemia do covid-19, todo o contato com os participantes fora realizado por meio online, utilizando-se a plataforma do Google Forms para aplicação do instrumento de coleta e avaliação do mesmo, e pelo aplicativo multiplataforma de mensagens instantâneas (WhatsApp), para melhor comunicação com os participantes.

O projeto foi encaminhado ao Comitê de Ética em Pesquisa (CEP) da Universidade Estadual de Londrina-PR, garantindo o cumprimento dos preceitos da Resolução 466/2012, da Comissão Nacional de Ética em Pesquisa/Conselho Nacional de Saúde. A realização da mesma ocorreu após a aprovação da pesquisa pelo CEP, sob a CAAE: 28941520.3.1001.5231 e o parecer de número: 3.989.981. Todos os indivíduos que aceitaram participar da coleta de dados, leram e aceitaram na plataforma online o Termo de Consentimento Livre e Esclarecido (TCLE).

\section{Resultados}

Foram convidados todos os profissionais da enfermagem a participar da pesquisa, totalizando 72 (100,0\%) funcionários, nas 24 horas de atendimento da unidade, sendo que destes 15 (20,8\%) são enfermeiros, 25 (34,7\%) técnicos de enfermagem e $32(44,4 \%)$ auxiliares de enfermagem.

Houve a exclusão de $8(11,1 \%)$ funcionários da pesquisa, por estarem de atestado; afastamento ou férias, conforme os critérios de exclusão da pesquisa. Assim, a amostra final contou com a participação de $32(44,4 \%)$ trabalhadores da unidade de saúde elegida para este estudo.

Foi realizado aplicação de dois questionários, um para dados demográficos e o outro para levantamento do conhecimento dos profissionais quanto a ressuscitação cardiopulmonar. Os questionários foram todos aplicados por meio online devido a pandemia do covid-19, sendo realizada pela plataforma do Google Forms.

Dados sobre a caracterização sociodemográfica são apresentados na Tabela 1. 
Tabela 1. Caracterização sociodemográfica dos participantes do estudo $(n=32)$. Assis, SP, Brasil.

\begin{tabular}{|c|c|c|}
\hline Característica & Nível & n $(\%)$ \\
\hline \multirow[t]{2}{*}{ Sexo } & Feminino & $27(84,4)$ \\
\hline & Masculino & $5(15,6)$ \\
\hline \multirow[t]{4}{*}{ Faixa etária } & 20 a 30 anos & $14(43,8)$ \\
\hline & 31 a 40 anos & $10(31,3)$ \\
\hline & 41 a 50 anos & $7(21,9)$ \\
\hline & 51 a 60 anos & $1(3,1)$ \\
\hline \multirow[t]{3}{*}{ Formação profissional } & Auxiliar de Enfermagem & $7(21,9)$ \\
\hline & Técnico em Enfermagem & $15(46,9)$ \\
\hline & Enfermeiro & $10(31,3)$ \\
\hline \multirow[t]{3}{*}{ Tempo de atuação profissional em urgência e emergência } & 1 a 5 anos & $19(59,4)$ \\
\hline & 5 a 10 anos & $8(25,0)$ \\
\hline & 10 a 20 anos & $5(15,6)$ \\
\hline \multirow[t]{2}{*}{ Participação em atividade de simulação realística urgência e emergência } & Não & $22(68,8)$ \\
\hline & Sim & $10(31,3)$ \\
\hline
\end{tabular}

Fonte: Autores.

Sobre o resultado do Teste de Conhecimento sobre Ressuscitação Cardiopulmonar, composto por 15 afirmações verdadeiras ou falsas, observou-se uma questão com $100 \%$ de acerto pelos participantes. A descrição dos acertos é disponível na Tabela 2 . 
Tabela 2. Teste de Conhecimento sobre Ressuscitação Cardiopulmonar (n=32). Assis, SP, Brasil.

\begin{tabular}{|c|c|c|}
\hline 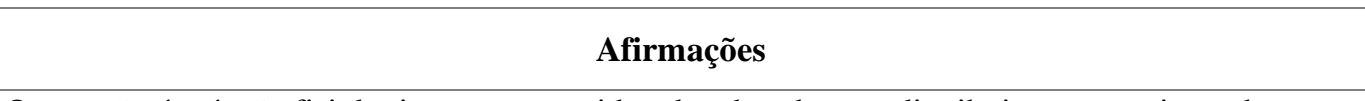 & Resposta & $\begin{array}{l}\text { Acertos } \\
\text { n }(\%)\end{array}$ \\
\hline $\begin{array}{l}\text { O coração é o órgão fisiologicamente considerado a bomba que distribui sangue oxigenado para } \\
\text { o pulmão e cérebro. }\end{array}$ & Falsa & $9(28,1)$ \\
\hline $\begin{array}{l}\text { A parada cardiopulmonar ou parada cardiorrespiratória (PCR), pode ser definida como a } \\
\text { ausência de atividade mecânica cardíaca, que é confirmada por ausência de pulso detectável, } \\
\text { ausência de responsividade, apneia ou respiração agônica (gasping). }\end{array}$ & Verdadeira & $27(84,4)$ \\
\hline $\begin{array}{l}\text { A PCR pode estar associada a uma alteração no eletrocardiograma, como uma taquicardia } \\
\text { ventricular sem pulso (TVSP), fibrilação ventricular (FV), atividade elétrica sem pulso (AESP) } \\
\text { ou assistolia }\end{array}$ & Verdadeira & $28(87,5)$ \\
\hline $\begin{array}{l}\text { Para reconhecer a PCR o profissional deverá chamar o paciente pelo nome, avaliar a respiração e } \\
\text { o pulso simultaneamente por } 10 \text { segundos. }\end{array}$ & Verdadeira & $27(84,4)$ \\
\hline O pulso a ser verificado deverá ser o carotídeo no lado do pescoço. & & $30(93,8)$ \\
\hline A posição dos braços deverá ser esticada na parte inferior do esterno, no meio do peito. & & $22(68,8)$ \\
\hline $\begin{array}{l}\text { Pacientes que se encontra no ambiente hospitalar dependem de um sistema de vigilância } \\
\text { adequado a fim de prevenir a PCR, porém quando ocorrer deve ser iniciado imediatamente a } \\
\text { RCP. }\end{array}$ & Falsa & $1(3,1)$ \\
\hline $\begin{array}{l}\text { As compressões quando não houver via aérea avançada: deverá realizar abertura de vias aéreas; } \\
\text { ventilação numa relação: } 30: 2 \text {, ou seja, } 30 \text { compressões e } 2 \text { ventilações. }\end{array}$ & Verdadeira & $32(100,0)$ \\
\hline $\begin{array}{l}\text { Na ventilação deverá ser realizado a liberação das vias áreas, que consiste em colocar a mão na } \\
\text { testa da pessoa e inclinar a cabeça para trás, em seguida levante o queixo da pessoa, colocando o } \\
\text { dedo indicador e médio sobre o maxilar inferior; erguer. }\end{array}$ & Verdadeira & $24(75,0)$ \\
\hline $\begin{array}{l}\text { Os papéis da equipe no atendimento deverão ser trocados a cada cinco ciclos de compressões e } \\
\text { respirações. Um ciclo consiste de } 30 \text { compressões e três respirações. }\end{array}$ & Falsa & $29(90,6)$ \\
\hline $\begin{array}{l}\text { Com via aérea avançada (máscara laríngea, tubo orotraqueal ou traqueostomia) as compressões } \\
\text { deverão ser contínuas a uma frequência } 100 \text { a } 120 / \text { minuto e } 1 \text { ventilação a cada } 6 \text { segundos ( } 10 \\
\text { respirações por minuto). }\end{array}$ & Verdadeira & $29(90,6)$ \\
\hline $\begin{array}{l}\text { O desfibrilador manual (uso exclusivo do médico) e/ou Desfibrilador externo automático - DEA } \\
\text { (uso de qualquer pessoa treinada), deverá ser utilizado o mais rápido possível, sendo possível } \\
\text { verificar o ritmo; em caso de ritmo chocável (Fibrilação Ventricular ou atividade elétrica sem } \\
\text { pulso), deverá ser aplicado } 1 \text { choque, e aguardar checagem do ritmo novamente. }\end{array}$ & Falsa & $4(12,5)$ \\
\hline $\begin{array}{l}\text { A amiodarona deverá ser utilizada quando os ritmos for FV / TV, sendo } 300 \mathrm{mg} \text { diluído em } 20 \text { a } \\
30 \mathrm{ml} \text {, podendo repetir } 150 \mathrm{mg} \text { em } 3 \text { a } 5 \text { minutos. }\end{array}$ & Verdadeira & $20(62,5)$ \\
\hline $\begin{array}{l}\text { A epinefrina deverá ser utilizada somente em PCR sem ritmos chocável, devendo ser iniciada: } \\
1,0 \mathrm{mg}(1: 10000) \text { IV cada } 3 \text { a } 5 \text { minutos. }\end{array}$ & Falsa & $5(15,6)$ \\
\hline $\begin{array}{l}\text { A hipotermia terapêutica é um cuidado recomendado para pessoas em coma, com retorno da } \\
\text { circulação espontânea após um evento de parada cardíaca. }\end{array}$ & Verdadeira & $18(56,3)$ \\
\hline
\end{tabular}

Fonte: Autores.

\section{Discussão}

Um estudo realizado em Goiás em 2017 traz que 50\% dos profissionais da enfermagem possui em média faixa etária acima dos 30 anos, estando de acordo com o que foi levantado nessa pesquisa, onde 56,3\% dos profissionais que participaram possui mais de 30 anos. Outro dado importante a se ressaltar é que a equipe de enfermagem representa no Brasil 1.449 .583 profissionais, sendo que deste 35,98\% encontram-se dentro da faixa acima dos 30 anos (Barbosa, Moraes-Filho, Pereira, Soares, Silva, \& Santos, 2018).

Em alguns estudos aponta-se, que as mulheres predominam na área da enfermagem, por tradição e cultura da profissão, porém, nos últimos anos vem se registrando a presença crescente de homens, o que afirma o surgimento de uma nova tendência da categoria (Costa \& Silva, 2021; Silva \& Silva, 2020; Bastos da Silva \& Silva, 2020). Mas, nesta pesquisa continuou demostrando que as mulheres ainda são a maioria da categoria 84,4\% dos profissionais da enfermagem da instituição, trazendo o mesmo de outros estudos encontrados na literatura, como um estudo desenvolvido em uma Unidade de Pronto Atendimento em Minas Gerais, onde 72,5\% dos profissionais são do sexo feminino (Martins et al., 2020). 
Referente ao tempo de atuação neste estudo mostrou que 50\% dos profissionais atuam menos de cinco anos na enfermagem, sendo um fator interessante, o qual metade dos profissionais atuante são recém formados, contradizendo outros estudos, que foi encontrado na literatura, que nos mostra que a equipe de enfermagem, em sua maioria 73,27\% está formada e atuante há mais de 5 anos. E em outros achados também houve o mesmo relato, de uma equipe com um tempo superior aos 5 anos de atuação (Moura, Brito, Rocha, \& Moura, 2019).

Em relação ao tempo de atuação em urgência e emergência pouco mais que a metade 59\% dos participantes, disseram que atuam de um a cinco anos, sendo que na maioria dos estudos encontrados foram apontados em média a maioria possuir 8 anos de atuação em unidades de urgência e emergência. Porém, torna-se importante ressaltar que está unidade a qual foi realizada a pesquisa, é uma unidade nova, onde possui apenas 6 anos de atendimento ao público, sendo assim, devemos considerar que pode ser um fator influenciador aos resultados desta pesquisa (Martins et al., 2020).

A equipe de enfermagem é o profissional, responsável pelo cuidado do paciente, e permanece por mais tempo ao lado destes, sendo que em sua maioria exige um cuidado 24 horas por dia. Desta forma, em situações de emergência provavelmente será o profissional que estará em contato primeiramente com o paciente, sendo assim torna-se indispensável este profissional saber o básico não somente das habilidades técnicas do atendimento, como a anatomia e fisiologia básica do corpo humano, sendo uma questão alarmante levantada nesta pesquisa que apenas $28,1 \%$ dos participantes responderam corretamente, quando referimos que o coração é nossa bomba, que distribui sangue oxigenado para todo nosso corpo, sendo que a maioria demostrou dificuldade no que se trata da fisiologia básica do nosso sistema cardíaco. Neste sentido, ressaltando este dado, por nenhum artigo revisado trazer informações para que pudéssemos comparar esta informação levantada no presente estudo.

A literatura preconiza que antes de iniciar o algoritmo de uma PCR é necessário realizar uma avaliação inicial no paciente que deverá ser pela sua responsividade, devendo o profissional chamar o paciente em alto e bom som, tocando em seu ombro, para que se tenha certeza que o mesmo esteja inconsciente. Após verificar a responsividade do paciente, deve-se realizar a checagem do pulso e da respiração do mesmo, estando ausente, solicitar ajuda, para que então se inicie o algoritmo da PCR conforme aponta as diretrizes da AHA (American Heart Association, 2020; 2015).

Quando avaliado o conhecimento dos participantes, no que se refere à identificação de uma PCR como citado a cima, a minoria 15,6\% respondeu incorretamente, um dado ruim, porém se comparado a outros estudos, que em grande parte; mostram que a maioria de $61,5 \%$, em um estudo, e $85,1 \%$ em outro estudo, dos profissionais deixaram de assinalar algum dos passo a passo para reconhecimento de uma PCR de extrema importância, como o nível de consciência, que no caso é inconsciente. Desta forma, os profissionais desta unidade demostrando em sua maioria que sabem identificar corretamente uma PCR (Prestes \& Menetrier, 2017).

A PCR pode estar associada a algumas arritmias cardíacas, que mudam os padrões cardíacos, como a velocidade e ou o ritmo do batimento cardíaco. Porém é importante ressaltarmos que existem quatro ritmos cardíacos que podem ocorrer em uma PCR, sendo aquelas que comprometem a circulação sistêmica, a fibrilação ventricular (FV) e taquicardia ventricular (TV) sem pulso, que são ritmos chocáveis, e a assistolia e ou presença de atividade elétrica sem pulso (AESP) que são considerados os ritmos não chocáveis. Destacando-se que os ritmos de Fibrilação Ventricular e Taquicardia Ventricular sem pulso (FV/TVSP), apresentam as maiores taxas de sobrevida, 36 a $37 \%$, desde que sejam reconhecidas corretamente e aplicado o choque assim que disponível. Na presente pesquisa observou-se que apenas $12,5 \%$ dos profissionais, não souberam identificar os ritmos que possa existir em uma PCR, uma porcentagem baixa se comparado com outro estudo, que revelou que 44,4\% dos profissionais consideraram apenas a assistolia como ritmo de PCR (Prestes \& Menetrier, 2017).

A RCP de qualidade exige algumas atenções durante a aplicação, as quais os profissionais deverá estar atendo para realizar corretamente, para que seja com qualidade, desta forma, a ACLS nos traz, passo a passo de como aplicar corretamente a RCP; devendo usar o salto de um lado na metade inferior do esterno no meio do peito; colocando a outra mão em cima da 
primeira mão; estique os braços e pressionar para baixo; as compressões deverá ser de pelo menos dois polegadas no peito da pessoa e a uma taxa de 100 a 120 compressões por minuto, e certificar-se que entre cada compressão que for parada completamente pressionando no peito e permitindo que a parede torácica retorne à sua posição natural, importante reforçar que ao inclinar-se ou descansar no peito entre as compressões pode manter o coração em recarga entre cada compressão e fazer CPR (compressões) menos eficaz. Quando realizada corretamente a RCP está associada a uma taxa de sobrevida de 16\%, quando comparada a RCP que é aplicada incorretamente com apenas 4\% de sobrevida (Zanini, Nascimento, \& Barra, 2006).

Neste sentido quando questionamos a posição dos braços durante a RCP, apenas 68,8\% responderam corretamente, sendo que é um fator alarmante, pois para uma RCP de alta qualidade é indispensável a posição correta dos braços durante a manobra.

O paciente em ambientes hospitalares que são potencias para uma PCR, deverá permanecer em uma vigilância constante, para que se previna tal fatalidade, e caso ocorra aja o mais rápido possível, deste modo a AHA em 2015 traz em suas diretrizes o sistema de time de resposta rápida (TRR) que podem ser eficazes na incidência e redução de PCR, pois, será essa equipe que será acionada sempre quando tiver um paciente que exija maior vigilância, e caso acontece a PCR inicie o atendimento.

Deste modo, observamos que é indispensável a vigilância, reconhecimento e solicitação de ajuda especializada, para que a sobrevida deste paciente seja maior e de qualidade. E ao questionarmos aos profissionais quanto a vigilância adequada para prevenção da PCR e ação imediata com RCP, 96,9\% dos profissionais responderam incorretamente a essa questão, esquecendo de um fator essencial; que é solicitar a ajuda especializada, sendo uma taxa alarmante, tendo em vista toda a complexidade e importância desta ação.

A PCR como já mencionado acima, pode estar associada a ritmos chocáveis (FV/TVSP), e quando existir, deverá ser administrado o choque quanto antes, e o Desfibrilador externo automático (DEA), é um aparelho simples e fácil de ser usado, podendo ser usado por qualquer pessoa, desde que seja treinada, através dele será possível verificar o ritmo; em caso de ritmo chocável, deverá ser aplicado 1 choque; e reiniciado a RCP por 2 minutos até o DEA avise sobre a verificação do ritmo novamente; devendo continuar este processo até que o Suporte Avançado de Vida assumir ou a vítima se movimentar. No caso dos hospitais, onde em sua maioria não há disponível o DEA, somente o desfibrilador manual, neste caso, necessita - se que a equipe médica esteja disponível 24 horas, tendo em vista que é um procedimento privativo do profissional médico (American Heart Association, 2020; 2015).

Ao avaliarmos os profissionais quanto ao uso do DEA e ou desfibrilador manual, apenas 12,5\% dos participantes responderam corretamente a esta questão, sendo que na questão dizia que deveria aguardado nova checagem do ritmo, contradizendo as diretrizes da AHA que nos orienta iniciar imediatamente a RCP após a aplicação do choque. Se compararmos com outra pesquisa, onde, aponta que 13,05\% dos enfermeiros e 41,02\% dos técnicos de enfermagem, não identificaram os ritmos cardíacos chocáveis, observando-se que é um fator de pouco conhecimento da equipe de enfermagem e que deve ser melhor trabalhado, para que ocorra melhora neste fator (Moura, Brito, Rocha, \& Moura, 2019).

A epinefrina é uma medicação que deverá ser utilizada sempre nas PCR, independentes se os ritmos for chocável ou não, devendo ser iniciada: 1,0 mg (1: 10000) IV cada 3 a 5 minutos em pacientes adultos, conforme os protocolos da ACLS, quando abordamos sobre essa temática, obtivemos um resultado alarmante, sendo que $84,4 \%$ dos participantes responderam incorretamente, pois na questão dizia que a epinefrina deverá ser utilizada somente em PCR sem ritmos chocável, o que contradiz as diretrizes da ACLS, como já apontado acima. Se comparar a ouros estudos, percebemos que mesmo sendo uma medicação utilizada no cotidiano da PCR, ainda existe muitas dúvidas dos profissionais, quanto a utilização da mesma, sendo que 81,5\% dos profissionais responderam parcialmente correto a questão que se tratava aos fármacos utilizados em PCR, em um estudo desenvolvido em uma UTI adulta de um hospital do sul do país (Prestes \& Menetrier, 2017). 
Os cuidados pós PCR é de extrema importância, porém durante todo nossa busca na literatura, a maioria dos achados, aponta somente o reconhecimento e atendimento a PCR em si, não trazendo como está o conhecimento dos profissionais quanto aos cuidados pós PCR. E ao questionarmos os profissionais quanto a hipotermia terapêutica que é um cuidado recomendado para pessoas em coma, realizando o retorno da circulação espontânea após um evento de PCR, apenas 56,3\% responderam corretamente, sabendo quais seriam um dos cuidados básicos no pós - PCR, sendo outro dado com grande déficit e muito importante o qual deverá ser trabalhado melhor com a equipe de enfermagem, considerando que tais cuidados determinara se haverá ou não lesões neurológicas neste paciente, que em sua maioria são irreversíveis (American Heart Association, 2020; 2015).

Sendo assim, a simulação realística torna-se uma estratégia vantajosa tanto para o profissional, quanto para o paciente, pois, permite que o profissional treine, aprenda e tire dúvidas, sem que aja danos ao paciente. Desta forma podendo melhorar a qualidade do atendimento prestado pela a equipe de enfermagem e a sobrevida destes pacientes. Neste sentido, a simulação realística segue três etapas: o briefing, a experiência da simulação e o debriefing.

O briefing é a primeira etapa da simulação, que tem por objetivo estabelecer um cenário que oriente o profissional antes do início da simulação. Já a experiência da simulação, é o acontecimento do cenário clínico, através de materiais e estratégias que aproximem o participante da realidade proposta (Jeffries, Dreifuerst, Kardong-Edgren, \& Hayden, 2015; Mazzo, 2017).

A última etapa é o debriefing, considerado o componente essencial desta estratégia, que acontece imediatamente após a simulação realística. O facilitador intencionalmente guia a discussão ao pensamento reflexivo, sem julgamento, não ameaçador, de modo que o profissional reconheça e verbalize espontaneamente suas falhas (Coutinho, Martins, \& Pereira, 2014).

\section{Considerações Finais}

Os resultados deste estudo demostraram a existência de grande déficit e lacunas de conhecimento da equipe de enfermagem, em diferentes passos da RCP conforme as diretrizes e atualizações da AHA e ACLS, sendo que é indispensável ter-se uma equipe preparada e que haja em sincronia no atendimento emergencial como a PCR, destacando-se que é considerada uma das mais graves emergência clinica que pode acometer ao paciente.

Desta forma, cria-se a necessidade de se capacitar tal equipe, de maneira continua podendo criar estratégias para sempre estar avaliando e melhorando as dificuldades que possa se levantar neste processo.

\section{Referências}

American Heart Association. (2015). Destaques da American Heart Association 2015. Atualização das diretrizes de RCP e ACE. http://cdn.laerdal.com/downloads/f3831/2015-AHA-Guidelines-Highlights-Portuguese.pdf

American Heart Association. (2020). Destaques das diretrizes de RCP e ACE de 2020 da American Heart Association. https://cpr.heart.org/-/media/cpr-files/cprguidelines-files/highlights/hghlghts_2020eccguidelines_portuguese.pdf

Barbosa, I. S. L., Moraes-Filho, I. M., Pereira, B. A., Soares, S. R., Silva, W., \& Santos, O. P. (2018). O conhecimento do profissional de enfermagem frente à parada cardiorrespiratória segundo as novas diretrizes e suas atualizações. Revista de Divulgação Científica Sena Aires, 7(2), 117-126.

Carabetta Jr, V. (2016). Metodologia ativa na educação médica. Revista De Medicina, 95(3), 113-121. https://doi.org/10.11606/issn.1679-9836.v95i3p113-121

Costa, B. M., \& Silva, D. A. da. (2021). Atuação da equipe de enfermagem em cuidados paliativos. Research, Society and Development, 10(2), e28010212553. https://doi.org/10.33448/rsd-v10i2.12553

Coutinho, V. R. D., Martins, J. C. A., \& Pereira, M. F. C. R. (2014). Construction and Validation of the Simulation Debriefing Assessment Scale (Escala de Avaliação do Debriefing associado à Simulação - EADaS). Revista de Enfermagem Referência, 4(2), 41-50. http://dx.doi.org/10.12707/RIII1392

Jeffries, P. R., Dreifuerst, K. T., Kardong-Edgren, S., \& Hayden, J. (2015). Faculty Development When Initiating Simulation Programs: Lessons Learned from the National Simulation Study. Journal of Nursing Regulation, 5(4), 17-23. https://doi.org/10.1016/S2155-8256(15)30037-5

Lucena, V. S., \& Silva, F. L. (2017). Assistência de enfermagem frente à parada cardiorrespiratória: um desafio permanente para o enfermeiro. Revista Científica FacMais, 9(4), 80-94. 
Research, Society and Development, v. 10, n. 3, e31110313310, 2021

(CC BY 4.0) | ISSN 2525-3409 | DOI: http://dx.doi.org/10.33448/rsd-v10i3.13310

Martins, A. R., Silva, M. L., Carvalho, M. T. M., Nascimento, J. S. G., Toledo, D. O., Silva, J. L., \& Alves, M. G. (2020). Ensino de ressuscitação cardiopulmonar por meio de videoaula. Revista de Enfermagem UFPE on line, 14, e243145. https://doi.org/10.5205/1981-8963.2020.243145

Mazzo, A. (2017). Simulação: conceitos básicos. In: Scalabrini Neto, A., Fonseca, A. S., Brandão, C. F. Simulação realística e habilidades na saúde. Rio de Janeiro, Atheneu.

Moura, J. G., Brito, M. P. S., Rocha, G. O. S., \& Moura, L. T. R. (2019). Conhecimento e atuação da equipe de enfermagem de um setor de urgência no evento parada cardiorrespiratória. Revista de Pesquisa: Cuidado é Fundamental Online, 11(3), 634-640. http://dx.doi.org/10.9789/2175-5361.2019.v11i3.634-640

Nacer, D. T., \& Barbieri, A. R. (2016). Sobrevivência a parada cardiorrespiratória intra-hospitalar: revisão integrativa da literatura. Revista Eletrônica De Enfermagem, 17(3). https://doi.org/10.5216/ree.v17i3.30792

Prestes, J. N., \& Menetrier, J. V. (2017). Conhecimento da equipe de enfermagem de uma unidade de terapia intensiva adulta sobre a parada cardiorrespiratória. Biosaúde, 19(1), 1-11.

Rocha, F. A. S., Oliveira, M. C. L., Cavalcante, R. B., Silva, P. C., \& Hates, H. F. (2012). Atuação da equipe de enfermagem frente a parada cardiorrespiratória intra-hospitalar. Revista de Enfermagem do Centro-Oeste Mineiro, 2(1), 141-150. https://doi.org/10.19175/recom.v0i0.100

Silva, B. B. da, \& Silva, D. A. da. (2020). Execução de estratégias e práticas seguras na prevenção de lesão por pressão. Research, Society and Development, 9(3), e102932653. https://doi.org/10.33448/rsd-v9i3.2653

Silva, K. R., Araújo, S. A. S. T., Almeida, W. S., Pereira, I. V. D. S., Carvalho, E. A. P., \& Abreu, M. N. S. (2017). Parada cardiorrespiratória e o suporte básico de vida no ambiente pré-hospitalar: o saber acadêmico. Saúde (Santa Maria), 43(1), 53-59.

Silva, L. F. de A., \& Silva, D. A. da. (2020). Sintomatologia depressiva em graduandos de Enfermagem no interior de São Paulo: uma abordagem epidemiológica. Research, Society and Development, 9(8), e884986465. https://doi.org/10.33448/rsd-v9i8.6465

Zanini, J., Nascimento, E. R. P., \& Barra, D. C. C. (2006). Parada e reanimação cardiorrespiratória: conhecimentos da equipe de enfermagem em Unidade de Terapia Intensiva. Revista Brasileira de Terapia Intensiva, 18(2), 143-147. https://doi.org/10.1590/S0103-507X2006000200007 